\title{
AN INTEGRATED MODEL FOR PREDICTING ENGINE FRICTION LOSSES IN INTERNAL COMBUSTION ENGINES
}

\author{
Mohammed Kamil ${ }^{3}$, M.M. Rahman ${ }^{1,2^{*}}$ and Rosli A. Bakar ${ }^{1}$ \\ ${ }^{1}$ Faculty of Mechanical Engineering, University of Malaysia Pahang \\ 26600 Pekan, Pahang, Malaysia \\ *E-mail: mustafizur@ump.edu.my \\ Phone: +(6)-094246239, Fax: +(6)-09-4246222 \\ ${ }^{2}$ Automotive Engineering Centre, University of Malaysia Pahang \\ 26600 Pekan, Pahang, Malaysia. \\ ${ }^{3}$ Faculty of Engineering, University of Tikrit, Tikrit, Iraq
}

\begin{abstract}
A comprehensive computer model (EFLP) has been developed for carrying out friction estimation and analysis of sparks ignited in reciprocating engines. EFLP considers five major loss components in an automotive engine: the crankshaft, piston, valvetrain, auxiliary components and pumping losses. Hydrodynamic, mixed, and boundary layer regimes are used to model the friction phenomena. The main building blocks of EFLP are empirical engine friction models based on experimental data. EFLP is constructed using MATAB-based engine code for estimating engine performance. The friction in a 4-cylinder 4-stroke engine is inspected. The results predicted by EFLP were validated according to a case study available in the literature. The validation showed that EFLP predictions are realistic and accurate.
\end{abstract}

Keywords: Engine friction; Pumping losses; Valvetrain friction; Auxiliary friction.

\section{INTRODUCTION}

Developing a model for determining friction loss is a top priority when modeling internal combustion engines, when working with any type of fuel(Azad, Ameer Uddin, \& Alam, 2012; Kamil, Rahman, \& Bakar, 2011, 2013; Kapilan, Ashok Babu, \& Reddy, 2010; Mat Yasin, Mamat, Sharma, \& Yusop, 2012; Rahim, Mamat, Taib, \& Abdullah, 2012). The accuracy of such a model is of significant importance for predicting transient behavior in the engine, and the corresponding fuel consumption. Unfortunately, friction losses are impossible to overcome completely. Friction minimization is therefore a major consideration in design and operation (Heywood, 1988; Kamil, Rahman, \& Bakar, 2011b; Rahman, Hamada, \& A. Aziz, 2013; Rahman, Hamada, Bakar, \& Maleque, 2012; Rahman, Hamada, \& Kadirgama, 2011). The lubrication of various moving components has been described as the key to the life of the engine (Hamada, Rahman, Abdullah, Bakar, \& A. Aziz, 2013; Hamada, Rahman, \& Aziz, 2012a, 2012b, 2012c; Hamada, Rahman, \& Aziz, 2013; Kamil et al., 2011b; Kamil, Rahman, Bakar, \& Kadirgama, 2012). Almost every car manufacturer has their own investigation and study group for friction in the engine, including Toyota (Nakada, 1994); Nissan (Hamai \& Kai, 1990); Ford (Wang, Chang, Hsieh, \& Lin, 1996) and GM (Goenka, Paranjpe, \& Jeng, 1992; Paranjpe \& Cusenza, 1992). With these models it is possible to estimate friction (and wear) for different engine speeds and loads. The most well-known and commonly used model is that of Patton, Nitschke, and Heywood 
(1989). Their model predicts friction mean effective pressure (FMEP) for SI engines, based on a combination of fundamental scaling laws and empirical results, included predictions of rubbing losses from the crankshaft, reciprocating, and valvetrain components, auxiliary losses from engine accessories, and pumping losses from the intake and exhaust systems. However, the data used to develop this model dates back to the mid-1980s, and thus, Sandoval and Heywood (2003) modified Paton's model. Their strategy involved comparing the predictions of Patton's model with more recent engine friction data, and determining the changes that needed to be made to certain conditions in this friction model. It was found that the pumping losses over the intake and exhaust strokes, and the conditions representing the cylinder gas pressure loading effects needed to be modified, and appropriate adjustments were made. The authors expanded the model to include lubricant viscosity as one of the variables, so that the effects of component temperatures on engine friction during cold start and warm-up transients could be predicted (Rahman, Kamil, \& Bakar, 2011; Rahman, Mohammed, \& Bakar, 2009a; Rahman, Mohammed, \& Bakar, 2009b, 2009c; Sandoval \& Heywood, 2003). Over the last two decades, large gains have been made, mostly through empirical methods, in reducing engine friction and improving its reliability and durability. Further significant improvements are possible, however, these improvements will be more difficult than in the past. It will be necessary to have a good mathematical friction and lubrication model for the robust design of mechanical components and for understanding how friction is developed, how it is distributed among components, and how it can be reduced. In addition, mathematical models are necessary to respond to one of the pressing needs for automotive industry-faster product development. Reliable predictive models are absolutely essential for reducing development time. This paper describes a model for the friction analysis of automotive engines using MATLAB codes.

\section{ENGINE FRICTION MODEL}

The model is developed from several components. Each component estimates the friction in a main part of the engine. The five components are the main building blocks including crankshaft friction, reciprocating friction, valvetrain friction, accessories friction, and pumping losses.

\section{Crankshaft Friction}

The friction in the crankshaft is sourced from three components and is calculated as Eq. (1):

$$
F M E P_{c s}=c_{b} \sqrt{\frac{\mu}{\mu_{o}}}\left(\frac{N D_{b}^{3} L_{b} n_{b}}{B^{2} L n_{c}}\right)+c_{s}\left(\frac{D_{b}}{B^{2} L n_{c}}\right)+1.35 \times 10^{-10}\left(\frac{N^{2} D_{b}^{2} L_{b} n_{b}}{n_{c}}\right)
$$

where $D_{b}$ is the bearing diameter, $\mu$ is the oil viscosity, $\mu_{o}$ is the reference viscosity, $L_{b}$ is the bearing length, $n_{b}$ is the number of bearings, $n_{c}$ is the number of cylinders, $L$ is engine stroke, $N$ is the engine speed, and $B$ is cylinder bore.

The first term is the friction in the main journal bearing of the crankshaft. The FMEP of a journal bearing array, with $n_{b}$ bearings, was scaled linearly with engine speed, assuming constant bearing clearance and oil viscosity (Heywood, 1988). The 
proportionality constant was suggested by Patton et al. (1989) as $c_{b}=3.03 \times 10^{-4}(\mathrm{kPa}$ min/rev-mm) for 10W-30 oil grade. The oil properties are included in the constant $c_{b}$. The presence of the term $\sqrt{\mu / \mu_{0}}$ was suggested by Sandoval and Heywood (2003) to generalize the correlation stated in Eq. (1), and is suitable for any other type of oil. The reference viscosity for $10 \mathrm{~W}-30$ oil grade is $10.8 \mathrm{cSt}$ at $100{ }^{\circ} \mathrm{C}$. The typical viscosity data for several different oil grades are listed in Table 1.

Table 1. Typical test data for engine oil viscosity (Rahman, Mohammed, Bakar, Muhamad, \& Kumaran, 2009)

\begin{tabular}{ccccccc}
\hline \multicolumn{2}{c}{ Oil grade } & $5 \mathrm{~W}-20$ & $5 \mathrm{~W}-30$ & $10 \mathrm{~W}-30$ & $10 \mathrm{~W}-40$ & $20 \mathrm{~W}-50$ \\
\hline \multirow{2}{*}{ Kinematic Viscosity } & $\mathrm{cSt}$ at $40{ }^{\circ} \mathrm{C}$ & 49.2 & 66.1 & 74.8 & 98.9 & 174.4 \\
& $\mathrm{cSt}$ at $100{ }^{\circ} \mathrm{C}$ & 8.6 & 11 & 10.8 & 14.4 & 19.1 \\
\hline
\end{tabular}

The second term in Eq. (1) represents the front and rear main bearing seal friction. The crankshaft bearing seals operate in a boundary lubrication regime, since the seals directly contact the crankshaft surface. As the normal force, the seal lip load and the friction force are constant and FMEP is independent of engine speed (Goenka et al., 1992). The proportionality constant was suggested by Goenka et al. (1992) as $c_{s}=1.22$ $\times 10^{5}\left(\mathrm{kPa}-\mathrm{mm}^{2}\right)$. The third term accounts for losses due to the transport of oil through the bearing, and accounts for turbulent dissipation, i.e. the work required to pump the fluids through flow restrictions (Patton et al., 1989).

\section{Reciprocating Friction}

The reciprocating parts producing friction are the piston skirt, piston rings and connected road. The friction from the piston ring has two components: one resulting from the ring tension and the other component from the gas pressure loading.

$$
F M E P_{\text {recip }}=c_{p s} \sqrt{\frac{\mu}{\mu_{o}}}\left(\frac{\bar{S}_{p}}{B}\right)+c_{p r}\left(1+\frac{500}{N}\right)\left(\frac{1}{B^{2}}\right)+3.03 \times 10^{-4} \sqrt{\frac{\mu}{\mu_{o}}}\left(\frac{N D_{b}^{3} L_{b} n_{b}}{B^{2} L n_{c}}\right)
$$

where $\bar{S}_{p}$ is the mean piston speed. The first term gives the piston friction, assuming a hydrodynamic regime. Viscosity scaling was also incorporated in this term, as proposed by Sandoval and Heywood (2003). In addition, the piston skirt length and skirt clearance were scaled directly with the bore $B$ (Sandoval \& Heywood, 2003). Again, the proportionality constant $c_{p s}$ was suggested by (Patton et al., 1989) as $\left(c_{p s}=294 \mathrm{kPa}\right.$ $\mathrm{mm}-\mathrm{s} / \mathrm{m})$; and included oil properties. The second term is for the friction component in the piston rings due to ring tension under a mixed regime. Piston ring tension and surface roughness were included to take into account the decreases in piston friction that have occurred in these two areas. The friction coefficient was assumed to be inversely proportional to the engine speed. The value of $1+500 / N$ was used to make the friction coefficient decrease by a factor of 1.8 from low to high speeds. The proportionality constant $\left(c_{p r}=4.06 \times 10^{4} \mathrm{KPa}-\mathrm{mm}^{2}\right)$ was proposed by Patton et al. (1989). The third term accounts for the hydrodynamic regime journal bearing friction from the connecting rod bearings. This term is similar to the bearing friction term in the crankshaft friction term. 


$$
F M E P_{\text {gasL }}=6.98 \frac{p_{i}}{p_{a}}\left[0.088 \sqrt{\frac{\mu}{\mu_{o}}} \varepsilon+0.128 \varepsilon^{\left(1.33-K \bar{S}_{p}\right)}\right]
$$

where $p_{i}$ and $p_{a}$ are the intake manifold pressure and atmospheric pressure respectively; and $\varepsilon$ is the compression ratio. It used the product of the intake pressure and a factor which included the compression ratio and mean piston speed derived from the physics of the compression process. The constant $K$ is equal to $2.38 \times 10^{-2} \mathrm{~s} / \mathrm{m}$ (Patton et al., 1989)

\section{Valvetrain Friction}

The term of the valvetrain friction includes estimates of camshaft, cam follower, and valve actuation mechanism friction, for a variety of valvetrain configurations (Patton et al., 1989). The model is able to predict friction for the common types of valve configurations, and is expressed as:

$$
\begin{aligned}
& F M E P_{v t}=244 \sqrt{\frac{\mu}{\mu_{o}}}\left(\frac{N n_{b}}{B^{2} L n_{c}}\right)+4.12+C_{f f}\left(1+\frac{500}{N}\right)\left(\frac{n_{v}}{L n_{c}}\right)+C_{r f}\left(\frac{N n_{v}}{L n_{c}}\right) \\
& +C_{o h} \sqrt{\frac{\mu}{\mu_{o}}}\left(\frac{l_{v \max }^{1.5} N^{0.5} n_{v}}{B L n_{c}}\right)+C_{o m}\left(1+\frac{500}{N}\right)\left(\frac{l_{v \max } n_{v}}{L n_{c}}\right)
\end{aligned}
$$

where $n_{v}$ is the number of valves and $l_{v \max }$ is the peak valve lift. The first term represents the camshaft bearing friction as a hydrodynamic regime. It is similar to that of the main crankshaft and connecting rod bearings friction. The constant $(244 \mathrm{kPa}-$ $\mathrm{mm}^{3}$ ) was suggested as the proportionality constant, plus an additional value of 4.12 $\mathrm{kPa}$ to account for the camshaft seals (Patton et al., 1989). The next two terms predict friction resulting from the relative motion between the cam lobe and the cam follower. The second term predicts friction in the mixed regime for flat follower configurations. The third term predicts rolling contact friction for roller follower configurations. Either the second term or the third term should be used and the second must be discarded depending on the type of follower being investigated. The forth term, oscillating hydrodynamic friction, predicts friction caused by relative motion between valvetrain components whose lubrication states were either completely or partially hydrodynamic, such as the valve lifter in the lifter bore or the valve in the valve guide. The friction coefficient was assumed to be proportional to the valve lift, and inversely proportional to the engine speed. The fifth term represents the oscillating mixed friction regime.

The constants $C_{f f}, C_{r f}, C_{o h}$ and $C_{o m}$ in the valvetrain term in Eq. (6) are dependent of the valvetrain configuration being considered in the model. Single Overhead Camshaft (SOHC) and Double Overhead Camshaft (DOCS) are the two main means of configuring the valvetrain. In SOHC, the camshaft is situated in the cylinder head, above the valves. The valves are opened and closed either directly, with a shim between the cam lobe and the valve stem, or via a rocker arm. SOHC engine valve configurations typically have two or three valves per cylinder. In the DOHC configuration, two camshafts are used in each cylinder head. This allows the easy implementation of four valves per cylinder setup. The disadvantages of such a setup are more weight, greater cost and increased complexity. Beyond this main classification, several designs are available under each configuration. Table 2 lists the most common types of valvetrain 
(Heywood, 1988) and Figure 1 presents some of these designs. Table 3 shows values for the constants $C_{f f}, C_{r f}, C_{o h}$ and $C_{o m}$ for different valvetrain configurations.

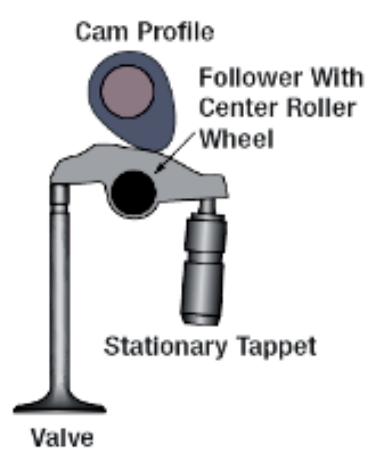

(a)

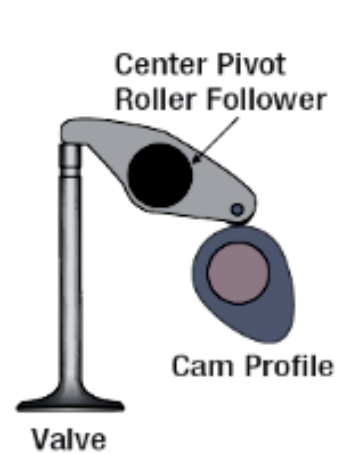

(b)

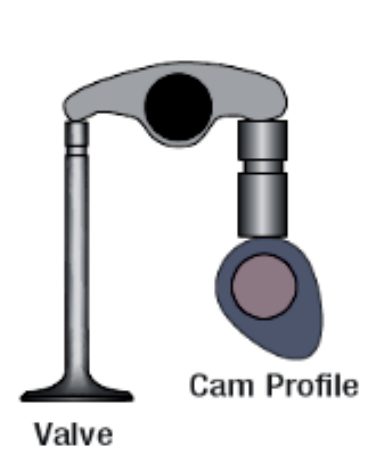

(c)

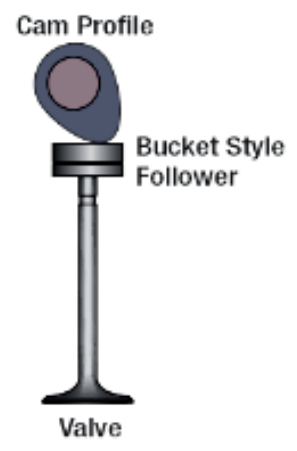

(d)

Figure 1. Various valvetrain designs (CPG, 2011); (a) Finger type follower (b) Center pivot rocker (c) Center pivot with lifter (d) direct active

Table 2. Valve train designs (Heywood, 1988).

\begin{tabular}{lll}
\hline Type I & OHC & Overhead cam; direct acing/ flat or roller follower \\
Type II & OHC & Overhead cam; End pivot rocker/ flat or roller follower \\
Type III & OHC & Overhead cam; Center pivot rocker/flat or roller follower \\
Type IV & CIB & Cam-in-block; rocker arm/flat or roller follower \\
\hline
\end{tabular}

Table 3. Constants for valvetrain friction term (Heywood, 1988)

\begin{tabular}{|c|c|c|c|c|c|}
\hline Configuration & Type & $\begin{array}{c}\text { Flat } \\
\text { Follower } \\
C_{f f}(\mathrm{KPa}- \\
\mathrm{mm})\end{array}$ & $\begin{array}{c}\text { Roller } \\
\text { Follower } \\
C_{r f}(\mathrm{KPa}- \\
\mathrm{mm}- \\
\mathrm{min} / \mathrm{rev})\end{array}$ & $\begin{array}{c}\text { Oscillating } \\
\text { Hydrodynamic } \\
C_{o h}(\mathrm{KPa}-\mathrm{mm}- \\
\text { min } / \mathrm{rev})^{1 / 2}\end{array}$ & $\begin{array}{l}\text { Oscillating } \\
\text { Mixed } \\
C_{o m}(\mathrm{KPa})\end{array}$ \\
\hline $\begin{array}{l}\text { Single overhead } \\
\text { cam (SOHC) }\end{array}$ & I & 200 & 0.0076 & 0.5 & 107 \\
\hline $\begin{array}{l}\text { Double overhead } \\
\text { cam (DOHC) }\end{array}$ & I & 133 & 0.0050 & 0.5 & 10.7 \\
\hline $\begin{array}{l}\text { Single overhead } \\
\text { cam }(\mathrm{SOHC})\end{array}$ & II & 600 & 0.0227 & 0.2 & 42.8 \\
\hline $\begin{array}{l}\text { Single overhead } \\
\text { cam }(\mathrm{SOHC})\end{array}$ & III & 400 & 0.0151 & 0.5 & 21.4 \\
\hline Cam in block (CIB) & IV & 400 & 0.0151 & 0.5 & 32.1 \\
\hline
\end{tabular}

\section{Accessory Friction}

The component of the accessory (or auxiliary) friction term is an empirical match to the sum of oil pump, water pump, and non-charging alternator friction. All the auxiliary component friction torques were assumed to be proportional to the engine displacement. (Heywood, 1988) suggest an accessory mean effective pressure $F M E P_{\text {aux }}$ of the form: 


$$
F M E P_{\text {aux }}=8.32+1.86 \times 10^{-3} N+7.45 \times 10^{-7} N^{2}
$$

The constants were determined from data from a group of small high-speed diesel engines.

\section{Pumping Losses}

The pumping losses term predicts intake and exhaust pumping mean effective pressures, each defined as the difference between cylinder pressure and atmospheric pressure integrated over the volume of the intake or exhaust stroke. The pumping friction losses mean effective pressure $F M E P_{p l}$ is calculated by Eq. (8)

$$
\text { FMEP }_{p l}=\left(p_{a}-p_{i}\right)+3 \times 10^{-3}\left(\frac{p_{i}}{p_{a}}\right)^{2}\left(\frac{\bar{S}_{p}^{2}}{n_{v}^{2} r_{i}^{4}}\right)+0.178\left(\frac{p_{i}}{p_{a}} \bar{S}_{p}\right)^{2}+3 \times 10^{-3}\left(\frac{p_{i}}{p_{a}}\right)^{2}\left(\frac{\bar{S}_{p}^{2}}{n_{v}^{2} r_{i}^{4}}\right)
$$

where $r_{i}$ and $r_{e}$ are the intake valve diameter/bore and exhaust valve diameter/bore ratios respectively. The first term is the intake manifold vacuum, calculated as the difference between atmospheric and intake pressure. The second term predicts the intake port and valve pressure drop. The third term estimates the exhaust system pressure drop, derived from measurements from typical production engine systems, and the fourth term is the exhaust valve and port pressure drop.

\section{Supplementary Models}

The atmospheric pressure $\left(p_{a}\right)$ is $101.325 \mathrm{kPa}$ throughout the simulation. As concerns the intake pressure $\left(p_{i}\right)$, it is assumed that the effective open area (from the air passage) remains constant for a throttle open higher than $80 \%$, and that when the throttle is fully closed, the intake manifold pressure is $10 \%$ of the absolute atmospheric pressure. Thus it is estimated as Eq.(9):

$$
p_{i}=p_{a} \times 0.9 \times \frac{\text { Throttleopen friction }}{0.8}+p_{a} \times 0.1
$$

The mean engine speed is calculated as Eq. (10):

$$
\bar{S}_{p}=2 L N
$$

\section{ENGINE FRICTION LOSSES PROGRAM (EFLP) VALIDATION}

The case study given in Patton et al. (1989) has been used for EFLP validation purposes. Table 4 lists the specifications of the engine and friction parameters used in this case. EFLP runs the simulation for an engine with the specifications in Table 4 and the results obtained agreed completely with those documented in Patton et al. (1989). Figure 2 depicts the comparison between the EFLP predictions and the results for the friction losses in different parts of the engine. The agreement is quite clear which reflects the validity of EFLP. Furthermore, Table 5 shows the exact FMEP values for each component and the total $F M E P$ of the engine for more precise comparison. 
Table 4. Engine parameters of the case study (Patton et al., 1989)

\begin{tabular}{lrlr}
\hline \multicolumn{1}{c}{ Parameter } & Value & \multicolumn{1}{c}{ Parameter } & Value \\
\hline Bore $(\mathrm{mm})$ & 86 & Intake valves/cylinder & 2 \\
Stroke $(\mathrm{mm})$ & 86 & Exhaust valves/cylinder & 35 \\
Number of cylinders & 4 & Intake valve diameter $(\mathrm{mm})$ & 31 \\
Compression ratio & 9 & Exhaust valve diameter $(\mathrm{mm})$ & 11 \\
Atmospheric pressure $(\mathrm{kPa})$ & 101 & Maximum valve lift $(\mathrm{mm})$ & 5 \\
Intake pressure $(\mathrm{kPa})$ & 101 & Number of crankshaft bearings & 56 \\
Exhaust pressure $(\mathrm{kPa})$ & 103 & Crankshaft bearing diameter $(\mathrm{mm})$ & 21 \\
Number of connecting rod bearings & 4 & Crankshaft bearing length $(\mathrm{mm})$ & 1 \\
Connecting rod bearing diameter $(\mathrm{mm})$ & 48 & Number of camshafts & SOHC \\
Connecting rod bearing length $(\mathrm{mm})$ & 42 & Valvetrain type & type I \\
& & & \\
\hline
\end{tabular}

Table 5. Detailed comparison for the FMEP values between EFLP (Patton et al., 1989)

\begin{tabular}{|c|c|c|c|c|}
\hline \multicolumn{2}{|l|}{ Main Components } & $\begin{array}{l}\text { FMEP } \\
(\mathrm{kPa})\end{array}$ & $\begin{array}{l}\text { FMEP }(\mathrm{kPa}) \\
\quad(\text { EFLP) }\end{array}$ & $\begin{array}{l}\text { Relative } \\
\text { error \% }\end{array}$ \\
\hline & Detailed components & & & \\
\hline \multirow{4}{*}{$\begin{array}{l}\text { Crankshaft } \\
\text { (total) }\end{array}$} & & 15.87 & 15.911 & 0.25 \\
\hline & $\begin{array}{l}\text { Crankshaft main } \\
\text { bearings }\end{array}$ & 6.59 & 6.5881 & 0.028 \\
\hline & Connecting rod bearings & 6.64 & 6.6381 & 0.028 \\
\hline & Crankshaft seals & 2.64 & 2.6853 & 1.71 \\
\hline \multirow[t]{4}{*}{ Piston (total) } & & 57.04 & 57.039 & 0.001 \\
\hline & Piston skirt & 29.4 & 29.4 & 0 \\
\hline & Piston ring tension & 7.32 & 7.3193 & 0.009 \\
\hline & Gas pressure & 20.32 & 20.3203 & 0.001 \\
\hline \multirow{5}{*}{$\begin{array}{l}\text { Valvetrain } \\
\text { (total) }\end{array}$} & & 25.8 & 25.5135 & 1.11 \\
\hline & Camshaft bearings & 5.56 & 5.2708 & 5.20 \\
\hline & Valvetrain flat follower & 12.4 & 12.4031 & 0.025 \\
\hline & $\begin{array}{l}\text { Valvetrain oscillating } \\
\text { mixed }\end{array}$ & 7.3 & 7.2992 & 0.01 \\
\hline & $\begin{array}{l}\text { Valvetrain oscillating } \\
\text { hydrodynamic }\end{array}$ & 0.54 & 0.5404 & 0.07 \\
\hline \multirow{5}{*}{$\begin{array}{l}\text { Pumping losses } \\
\text { (total) }\end{array}$} & & 20.45 & 20.6454 & 0.95 \\
\hline & Intake manifold & 2.78 & 2.8308 & 1.82 \\
\hline & Intake valves & 0 & 0 & 0 \\
\hline & Exhaust valves & 13.16 & 13.1649 & 0.037 \\
\hline & Exhaust system & 4.51 & 4.5997 & 1.98 \\
\hline $\begin{array}{l}\text { Accessory } \\
\text { (total) }\end{array}$ & & 20.28 & 20.6059 & 1.6 \\
\hline $\begin{array}{ll}\text { Overall } & \text { Total } \\
\text { FMEP } & \\
\end{array}$ & & 139.44 & 139.6659 & 0.16 \\
\hline
\end{tabular}




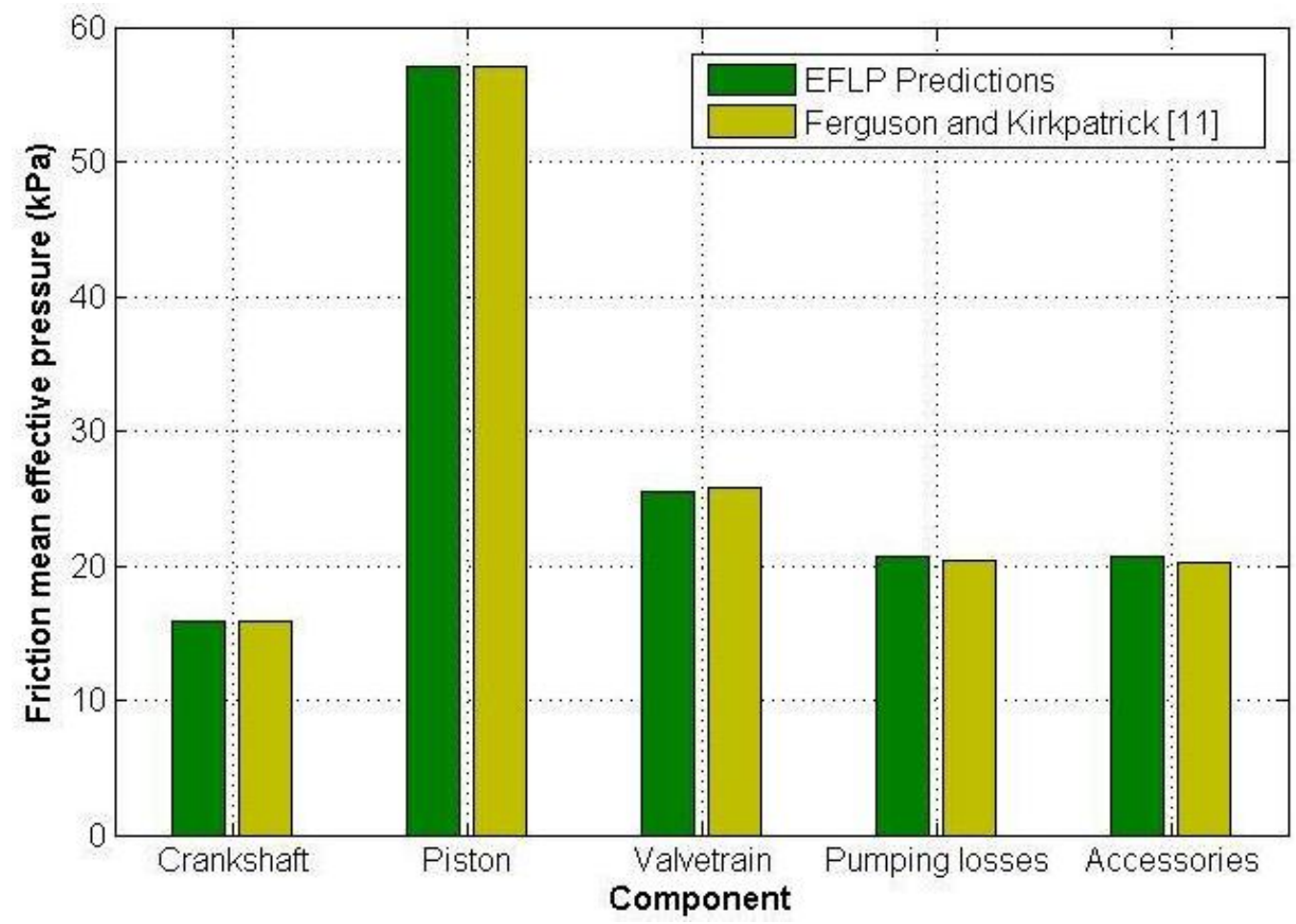

Figure 2. Comparison of FMEP predictions between EFLP, and Patton et al. (1989)

\section{RESULTS AND DISCUSSION}

Reducing the friction losses and wear of the parts subjected to relative motion is the main aim of the engine design. Engine speed is the major operation parameter controlling the friction losses. This is true of all the empirical relationships that have been shown to correlate with experimental observations on the friction in four stroke engines. The empirical relationships documented in Patton et al. (1989) are examples of this trend. In this section attention is therefore paid to exploring the trends of the different components of friction loss with engine speed, according to the predictions of EFLP. The results are presented here for an engine with the key parameters listed in Table 4. The friction behavior of the different engine components are presented in the following section. The contribution of each individual part is highlighted to assess the weight of each part. Figure 3 presents the trends of crankshaft friction. Clearly, the friction loss of the crankshaft bearing seat does not depend on engine speed and remains constant for all investigated speed ranges. Furthermore, it represents the most basic elements of total crankshaft friction; approximately $80 \%$ of the friction was accounted for by the hydrodynamic and turbulent dissipation term. Figure 4 presents the piston friction behavior with engine speed. The skirt and connecting rod bearing FMEP increase linearly with engine speed, while the piston rings and gas pressure FMEP decrease with engine speed. At higher speeds the majority of the friction is from the piston skirt. This is because the piston skirt is designed to meet the side thrust forces originating from the rotation of the connecting rod; which augment the increasing piston speed. 


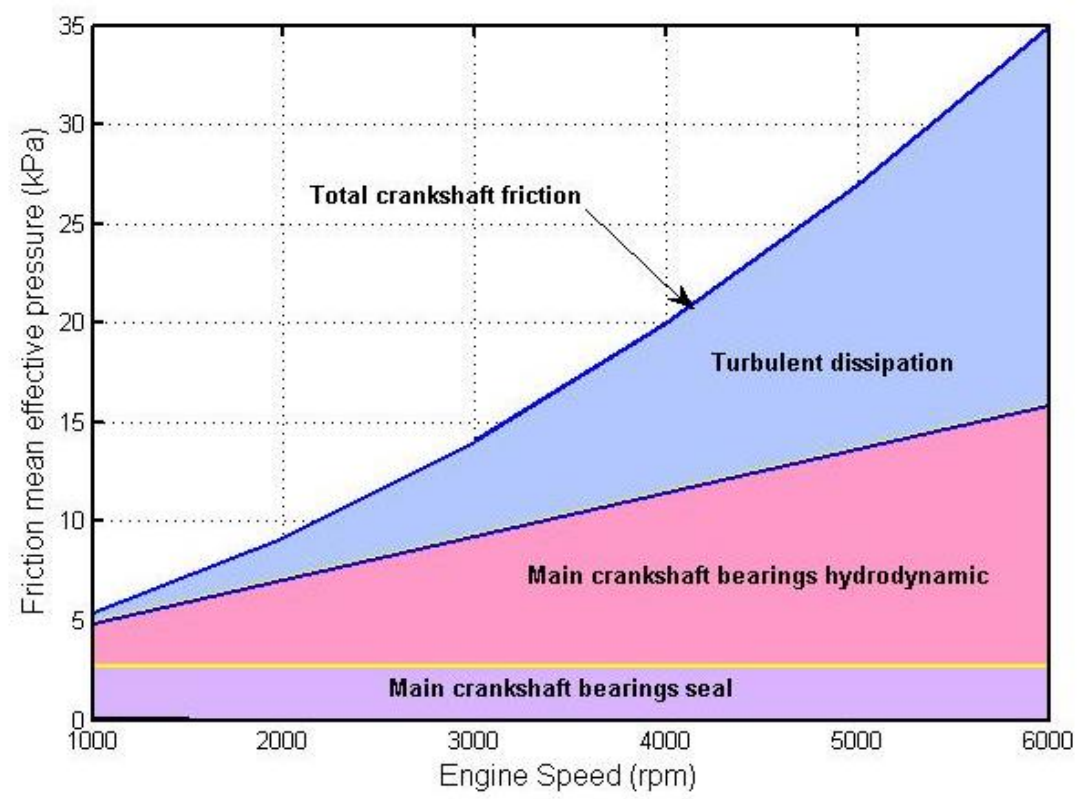

Figure 3. Crankshaft friction behavior with engine speed

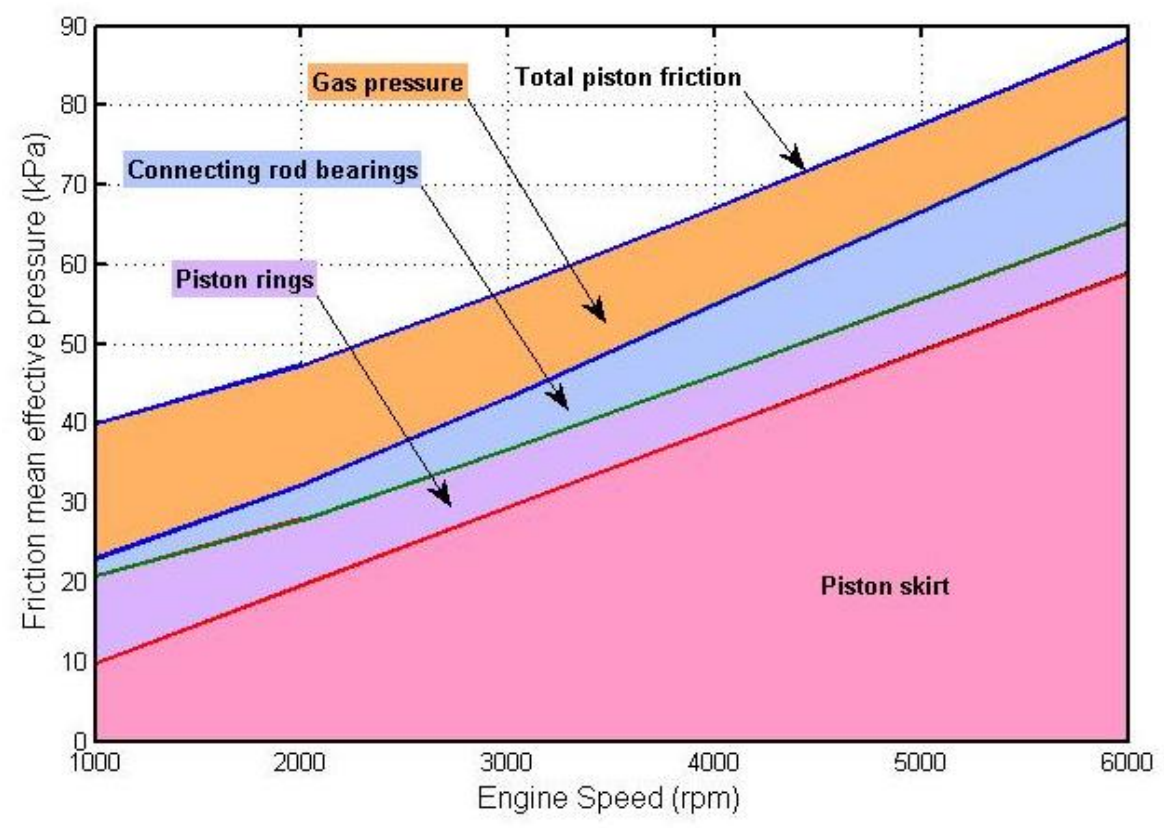

Figure 4. Piston friction behavior with engine speed

Figure 5 shows the friction losses in the valvetrain. It is notable that valvetrain is the main source of friction losses in the engine over the entire engine speed range. This is due to the high loads carried by the valvetrain over the entire speed range. More specifically, at lower speeds, the valvetrain is primarily under loads due to spring forces, while at higher speeds the inertia forces of the component masses dominate. It can also be seen from the shape of the $F E M P_{v t}$ versus the speed curve that the cam follower interface contributes the largest friction loss due to the very high loads and small contact areas. The other characteristic feature seen here is the higher loss at lower speeds which is contradictory to other component behavior. Figure 6 describes the constituents of the pumping loss friction. The pumping mean effective pressure is the sum of the pressure 
drops across flow restrictions during the intake and exhaust strokes. It is a measure of the work required to move the fuel-air mixture into and out of an engine (Ferguson and Kirkpatrick, 2001). The major losses for the tested condition are in the intake system which depends on the manifold and ambient pressures only.

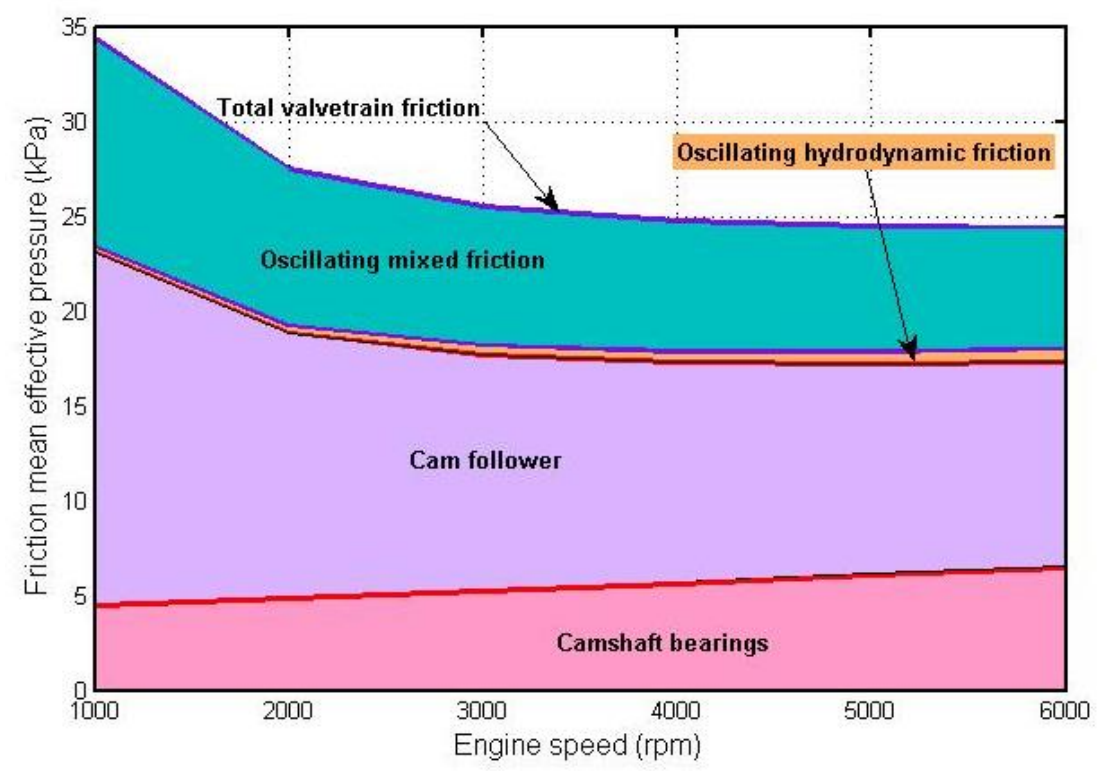

Figure 5. Valvetrain friction behavior with engine speed

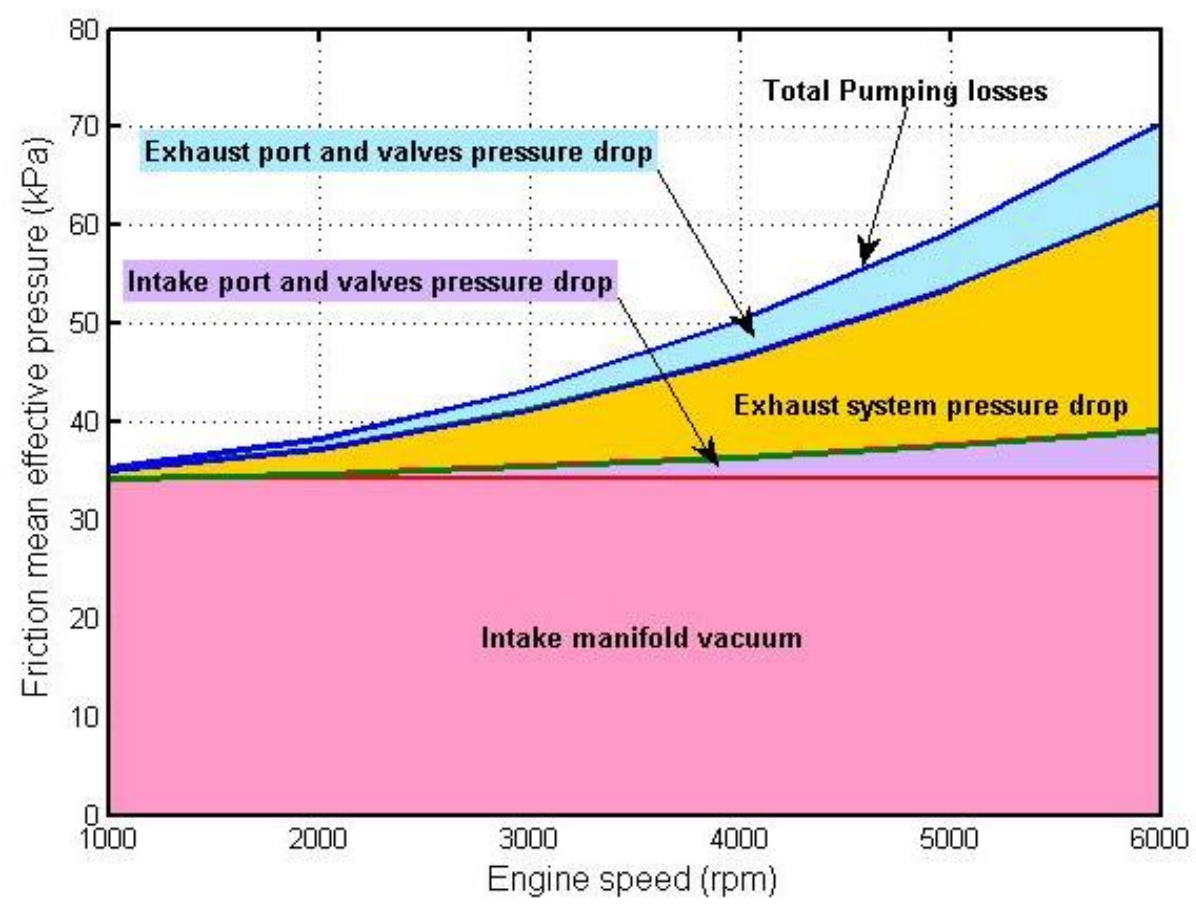

Figure 6. Pumping loss behavior with engine speed

Figure 7 presents the total engine FMEP in its components and shows the weight of each component. Evidently, the components losses all increase with engine speed except 
that of the valvetrain. In addition, the main contributor is the piston friction, followed by the pumping losses. Additional details regarding the contribution of each component to the total friction power are given in Figure 8. Figure 9 is illustrated to investigate the effect of the throttle position on the lost friction power. Insignificant differences are seen for the entire engine speed range inspected.

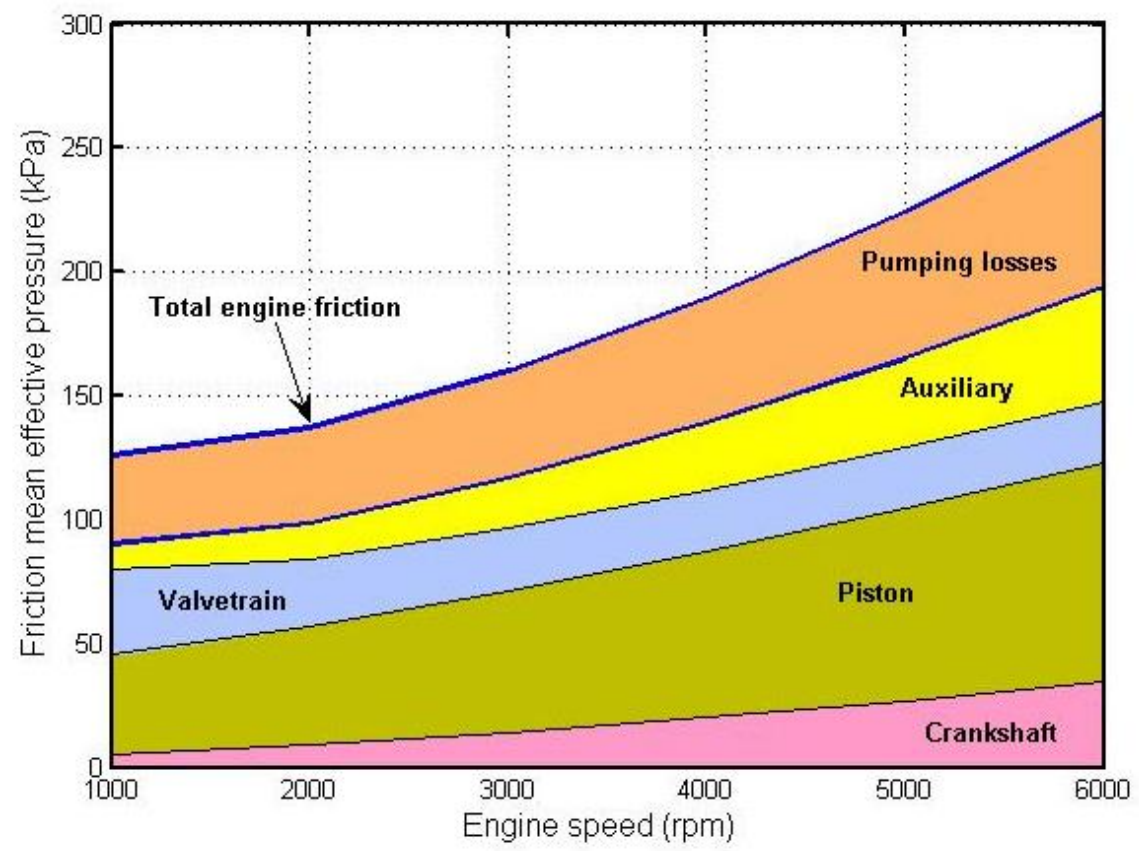

Figure 7. Engine friction component behavior with engine speed

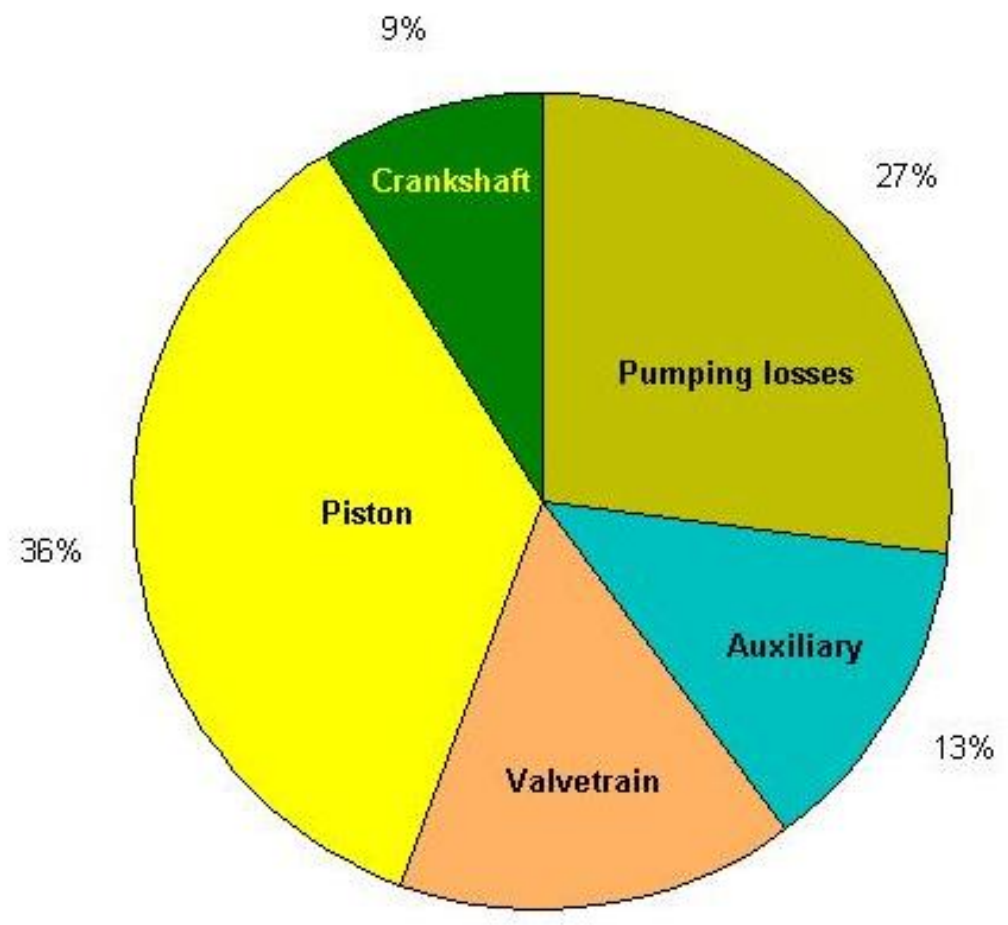

$16 \%$

Figure 8. Contribution of component friction to total engine friction power 


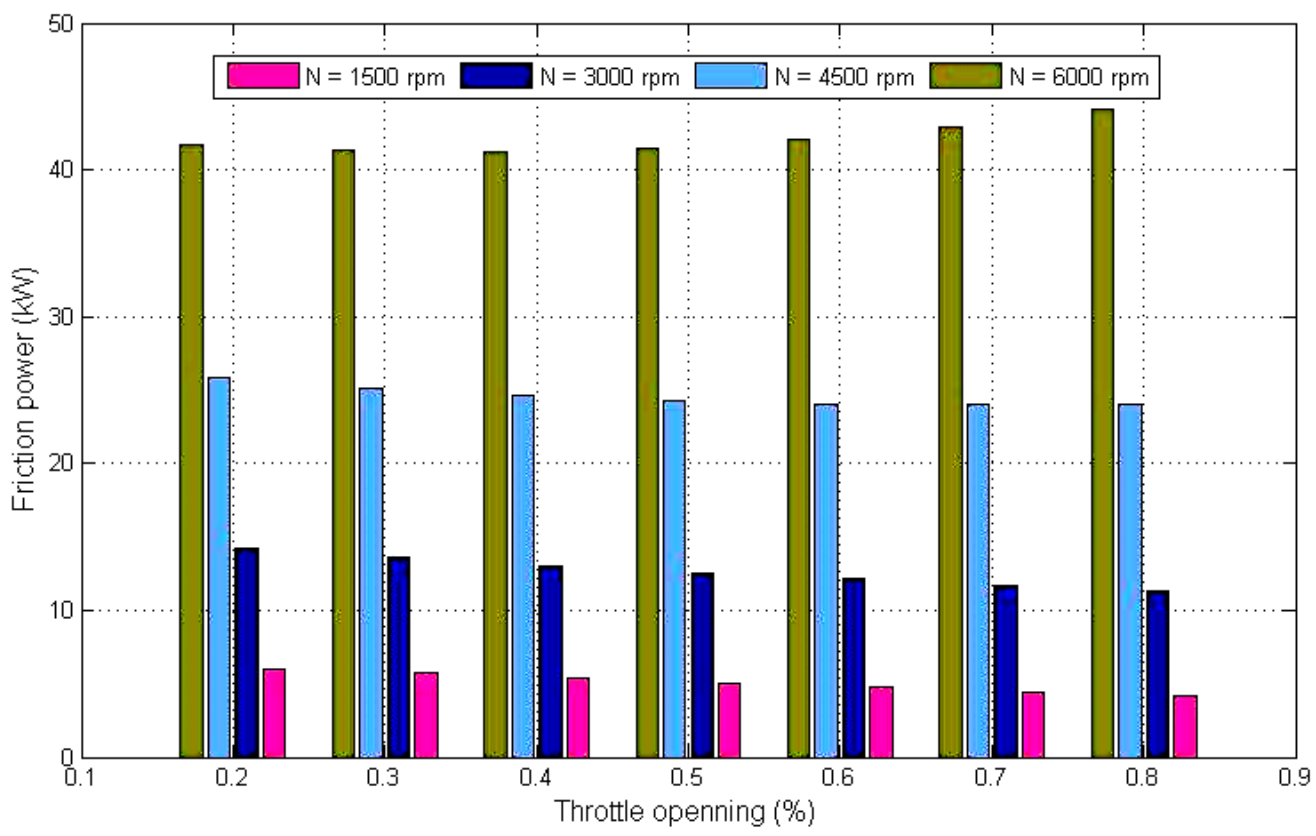

Figure 9. Friction power variation with engine throttle for different engine speeds

\section{CONCLUSIONS}

This paper gives an overview of EFLP, a comprehensive computer analysis model for friction analysis of automotive engines. Details of the mathematical formulation of the friction phenomenon were first described. EFLP provides a unique tool to examine the impact of engine design changes on engine friction. As a result of the difficulty in accurately measuring friction in a running engine, a comprehensive mathematical tool, such as the one described in this paper, is invaluable in designing inherently low-friction engines and in minimizing friction for existing designs. Case studies, such as the one presented in this paper, are very easy to perform with EFLP because of the flexibility of the analysis models.

\section{ACKNOWLEDGMENT}

The authors would like to express their gratitude to the University of Malaysia Pahang for providing laboratory facilities and financial support (RDU110332).

\section{REFERENCES}

Azad, A. K., Ameer Uddin, S. M., \& Alam, M. M. (2012). A comprehensive study of di diesel engine performance with vegetable oil: An alternative boi-fuel source of energy. International Journal of Automotive and Mechanical Engineering, 5, 576-586.

Goenka, P., Paranjpe, R., \& Jeng, Y. (1992). Flare: An integrated software package for friction \& lubrication analysis of automotive engines - part $i$ : Overview \& applications. SAE Technical Paper No. 920487.

Hamada, K. I., Rahman, M. M., Abdullah, M. A., Bakar, R. A., \& A. Aziz, A. R. (2013). Effect of mixture strength and injection timing on combustion 
characteristics of a direct injection hydrogen-fueled engine. International Journal of Hydrogen Energy, 38(9), 3793-3801.

Hamada, K. I., Rahman, M. M., \& Aziz, A. R. A. (2012a). Development of a computational fluid dynamics model for direct injection hydrogen fueled engine. International Review of Mechanical Engineering, 6(3), 675-679.

Hamada, K. I., Rahman, M. M., \& Aziz, A. R. A. (2012b). Influence of engine speed and mixture strength on instantaneous heat transfer for direct injection hydrogen fuelled engine. Energy Education Science and Technology Part A: Energy Science and Research, 30(SPEC .ISS.1), 153-172.

Hamada, K. I., Rahman, M. M., \& Aziz, A. R. A. (2012c). Time-averaged heat transfer correlation for direct injection hydrogen fueled engine. International Journal of Hydrogen Energy, 37(24), 19146-19157.

Hamada, K. I., Rahman, M. M., \& Aziz, A. R. A. (2013). Parametric study of instantaneous heat transfer based on multidimensional model in direct-injection hydrogen-fueled engine. International Journal of Hydrogen Energy, 38(28), 12465-12480.

Hamai, T., \& Kai, S. (1990). Development of a friction prediction model for high performance engines. . Society of Tribologists and Lubrication Engineers, 47, 567-573.

Heywood, J. B. (1988). Internal combustion engine fundamentals. New York: McGrawHill.

Kamil, M., Rahman, M. M., \& Bakar, R. A. (2011). Performance evaluation of external mixture formation strategy in hydrogen fueled engine. Journal of Mechanical Engineering and Sciences, 1, 87-98.

Kamil, M., Rahman, M. M., \& Bakar, R. A. (2013). Integrated simulation model for composition and properties of gases in hydrogen fueled engine. International Journal of Automotive and Mechanical Engineering, 8, 1242-1155.

Kamil, M., Rahman, M. M., Bakar, R. A., \& Kadirgama, K. (2012). Modeling of si engine for duel fuels of hydrogen, gasoline and methane with port injection feeding system. Energy Education Science and Technology Part A: Energy Science and Research, 29(2), 1399-1416.

Kapilan, N., Ashok Babu, T. P., \& Reddy, R. P. (2010). Improvement of performance of dual fuel engine operated at part load. International Journal of Automotive and Mechanical Engineering, 2, 200-210.

Mat Yasin, M. H., Mamat, R., Sharma, K. V., \& Yusop, A. F. (2012). Influence of palm methyl ester (pme) as an alternative fuel in multicylinder diesel engine. Journal of Mechanical Engineering and Sciences, 3, 331-339.

Nakada, M. (1994). Trends in engine technology and tribology. Tribology International, (27), 3-8.

Paranjpe, R., \& Cusenza, A. (1992). Flare: An integrated software package for friction \& lubrication analysis of automotive engines - part ii: Experimental validation. . SAE Technical Paper No. 920488.

Patton, K. J., Nitschke, R. G., \& Heywood, J. B. (1989). Development and evaluation of a performance and efficiency model for spark-ignition engines. SAE Technical Paper No. 890836.

Rahim, R., Mamat, R., Taib, M. Y., \& Abdullah, A. A. (2012). Influence of fuel temperature on a diesel engine performance operating with biodiesel blended. Journal of Mechanical Engineering and Sciences, 2, 226-236. 
Rahman, M. M., Hamada, K. I., \& A. Aziz, A. R. (2013). Characterization of the timeaveraged overall heat transfer in a direct-injection hydrogen-fueled engine. International Journal of Hydrogen Energy, 38(11), 4816-4830.

Rahman, M. M., Hamada, K. I., Bakar, R. A., \& Maleque, M. A. (2012). Heat transfer analysis inside exhaust port for a hydrogen fueled port injection engine. Advanced Science Letters, 14(1), 239-243.

Rahman, M. M., Hamada, K. I., \& Kadirgama, K. (2011). Heat transfer of intake port for hydrogen fueled port injection engine: A steady state approach. International Journal of Physical Sciences, 6(16), 3969-3976.

Rahman, M. M., Kamil, M., \& Bakar, R. A. (2011). Engine performance and optimum injection timing for 4-cylinder direct injection hydrogen fueled engine. Simulation Modelling Practice and Theory, 19(2), 734-751.

Rahman, M. M., Mohammed, M. K., \& Bakar, R. A. (2009a). Air fuel ratio on engine performance and instantaneous behavior of crank angle for four cylinder direct injection hydrogen fueled engine Journal of Applied Sciences, 9, 2877-2886.

Rahman, M. M., Mohammed, M. K., \& Bakar, R. A. (2009b). Effects of air-fuel ratio and engine speed on performance of hydrogen fueled port injection engine. Journal of Applied Sciences, 9(6), 1128-1134.

Rahman, M. M., Mohammed, M. K., \& Bakar, R. A. (2009c). Effects of air fuel ratio and injection timing on performance for four-cylinder direct injection hydrogen fueled engine. European Journal of Scientific Research, 25(2), 214-225.

Sandoval, D., \& Heywood, J. B. (2003). An improved friction model for spark-ignition. . SAE Technical Paper No. 2003-01-0725.

Wang, C. C., Chang, Y. J., Hsieh, Y. C., \& Lin, Y. T. (1996). Sensible heat and friction characteristics of plate fin-and-tube heat exchangers having plane fins. International Journal of Refrigeration, 19(4), 223-230. 